\title{
INTERPRETAÇÃO DE ÁREAS ÚMIDAS POR MEIO DE IMAGENS DE SATÉLITE LANDSAT: ESTUDO APLICADO AO MUNICÍPIO DE ANHUMAS - SP.
}

\author{
Rodrigo Coladello Oliveira, Lucas Prado Osco, Marcos Norberto Boin \\ Universidade do Oeste Paulista - UNOESTE. Pós-Graduação no Mestrado em Meio Ambiente e Desenvolvimento \\ Regional, Presidente Prudente - SP. E-mail: rodcoladello@hotmail.com
}

\section{RESUMO}

No presente trabalho optou-se por utilizar imagens do satélite Landsat 5 (Sensor TM), dando enfoque à identificação de áreas úmidas inseridas na unidade de mapeamento litoestratigráfico $\mathrm{Ka}_{\text {IV }}$ no município de Anhumas - SP, apresentando suas relações com o uso territorial local. Parte da metodologia priorizou destacar os ambientes fluviais por meio de diferentes combinações das bandas do Landsat 5 (Sensor TM), uma vez que as áreas onde se concentram os corpos d'água superficiais apresentam refletâncias divergentes em relação às demais coberturas e usos locais. Assim, com a finalidade de comprovarem-se as informações levantadas via sensoriamento, um estudo em campo foi realizado, buscando verificar áreas específicas apontadas nas imagens. Conclui-se, portanto, que para o reconhecimento específico destas áreas úmidas, as imagens Landsat são limitadas (devido a sua resolução espacial), tornando necessário um conhecimento aprofundado do local estudado.

Palavras-chave: Landsat. Geologia. Geomorfologia. Lençóis Suspensos. Planícies Aluviais.

\section{WET AREAS OF INTERPRETATION THROUGH SATELLITE LANDSAT IMAGES : STUDY THE APPLIED ANHUMAS COUNTY - SP.}

\begin{abstract}
In the present work we chose to use Landsat 5 satellite images (TM Sensor) by focusing on the identification of wetlands inserted in the lithostratigraphic mapping unit KalV in the municipality of Anhumas - SP, with its relations with the local land use. Part of the methodology prioritized the river environments through different combinations of bands of the Landsat 5 (TM sensor), since the areas that concentrated bodies of surface water have differing reflectance compared to other local uses. Thus, in order to prove up the information gathered via mapping, a field study was conducted in order to verify specific areas identified in the images. Therefore, it's concluded that, for the specific recognition of these wetlands, the Landsat 5 images are limited (due to its spatial resolution), requiring a better and profound understanding of the studied area.
\end{abstract}

Key-words: Landsat. Geology. Geomorphology. Water Bodies. Floodplains. 
INTRODUÇÃO

O presente trabalho teve como objetivo levantar, através de imagens Landsat 5 , os afloramentos dos lençóis freáticos suspensos na unidade de mapeamento Ka|v, da Formação Adamantina, Grupo Bauru, associando as características geológicas aos elementos da paisagem. Subentende-se que os diferentes afloramentos de corpos d'água são determinados em razão de seus ambientes de sedimentação, que imprimem características peculiares as diferentes formações litológicas, tais como: composição mineralógica; granulométrica; de permeabilidade; dentre outras, gerando diferentes condições geoambientais para a ocorrência dos lençóis freáticos, que são refletidas nas características engendradas e consolidadas pelo próprio meio físico. As forças internas, comandadas por processos geológicos, são responsáveis pela estruturação do relevo na paisagem. A partir de então, o modelado é esculpido por agentes externos, definindo suas feições esculturais. Assim, dependendo da escala de trabalho adotada para o estudo, torna-se possível observar as diferentes implicações geomorfológicas, tanto nas vertentes, quanto nos ambientes fluviais, definindo-se assim diferentes táxons de abordagem (ROSS, 1992).

Os depósitos da Formação Adamantina (Grupo Bauru) apresentam variações regionais que motivaram diferentes autores (SOARES \& FIORI, 1976; ALMEIDA et al., 1980; IPT, 1981; FERNANDES \& COIMBRA, 2000) a discutirem sua distribuição, posição estratigráfica e ambiente deposicional, dos quais definirão conjuntos litológicos com características semelhantes. Neste sentido, a classificação proposta por Almeida et al. (1980), sugere que a Formação Adamantina subdivida-se em cinco unidades de mapeamento $\left(K a_{1}, K a_{\|}, K a_{\| l}, K a_{\| v}\right.$ e $\left.K a_{v}\right)$, de caráter informal. Neste sentido, o presente trabalho tem como finalidade realizar a identificação e posterior analise referente às áreas úmidas encontrados no recorte de estudo - unidade de mapeamento KaIV (Quadro 1) - localizado no município de Anhumas e suas relações com o uso e cobertura da terra.

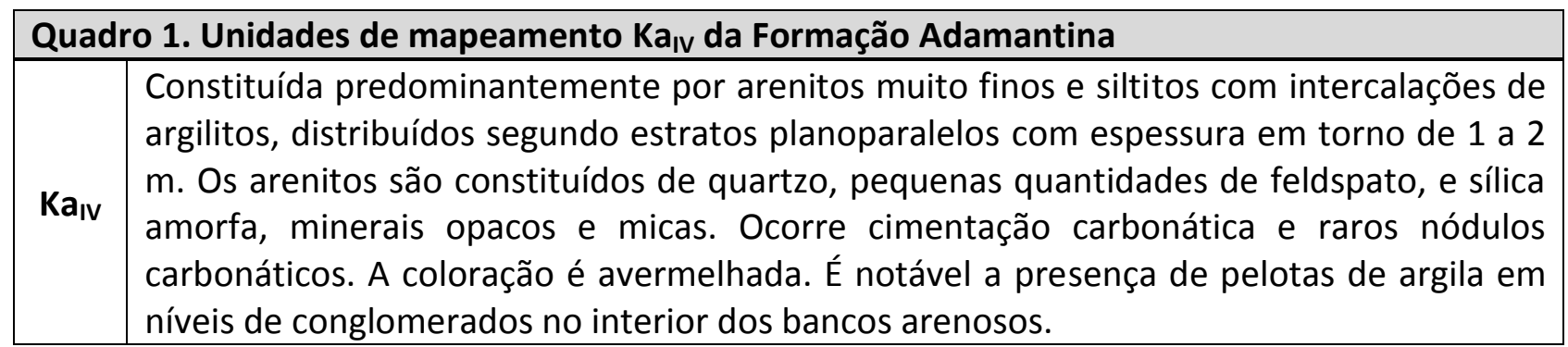
Fonte: ALMEIDA, et al. (1980). 


\section{A ÁREA DE ESTUDO}

O município de Anhumas - SP encontra-se localizado próximo à região central da Bacia Sedimentar do Paraná (unidade geotectônica sobre a Plataforma Sul-Americana), onde há a ocorrência de arenitos do Grupo Bauru, responsáveis por recobrir uma vasta parte do território paulista (MELO et al., 1982) (Figura 1). Em termos geológicos, a Formação Adamantina (classificação proposta por Almeida et al., 1980), aflora por toda a área ocupada pelo município, distribuindo-se localmente nas unidades de mapeamento litoestratigráfico: Kal, Kaıv e Kav (Almeida et al., op. cit.). O recorte espacial adotado neste estudo refere-se à unidade de mapeamento litoestratigráfico $\mathrm{Ka}_{\mathrm{IV}}$, face à expressiva quantidade de lençóis freáticos suspensos ocorrentes na unidade, onde se reflete as características litológicas desta unidade na região.

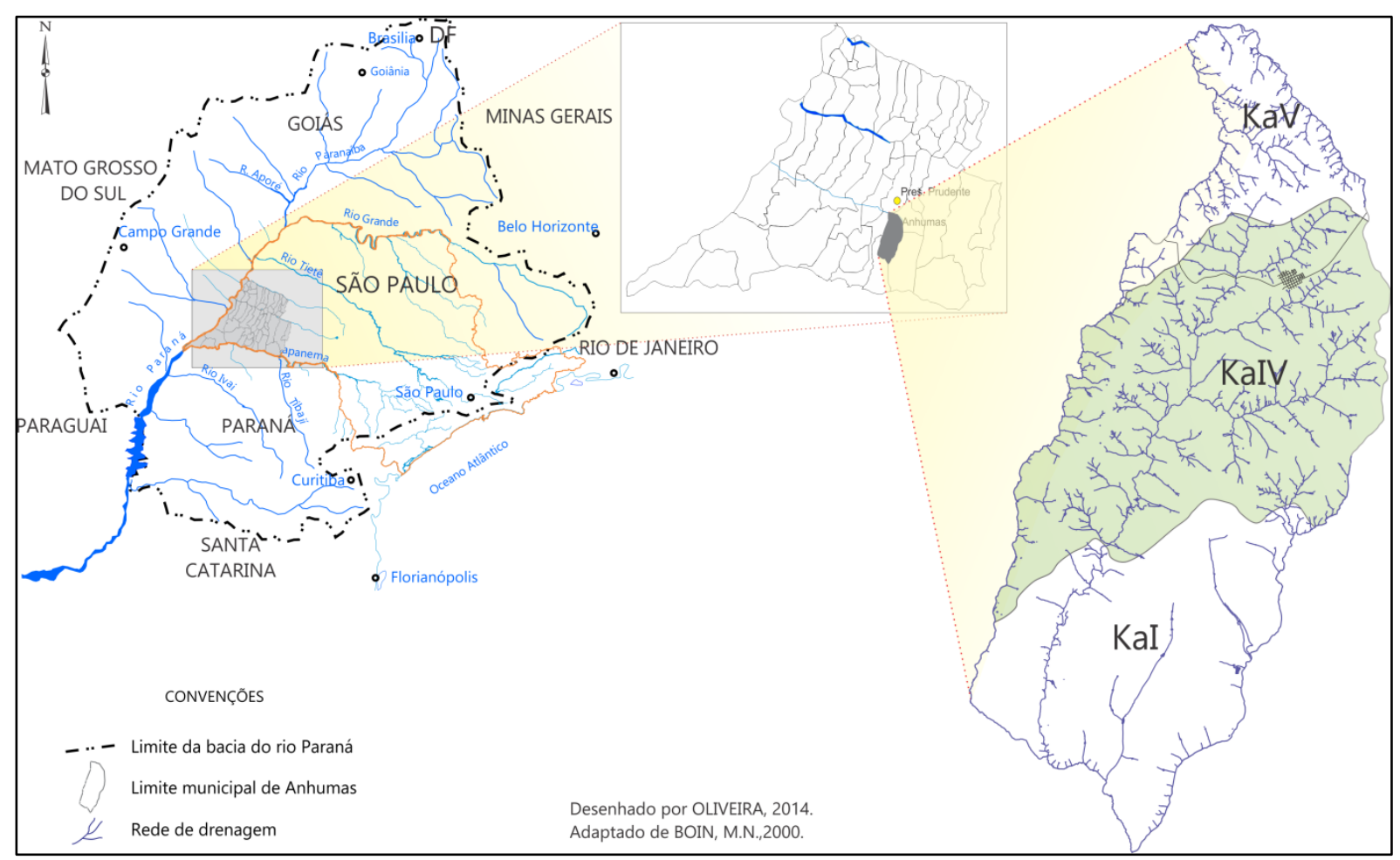

Figura 1. Localização da área de estudo.

\section{METODOLOGIA}

A confecção deste trabalho deu-se, preliminarmente, a partir do levantamento bibliográfico referente à região de estudo. A escolha teórica adotada fundamentou-se nos textos de Almeida et al. (1980), IPT (1981), Embrapa (1999), DAEE (2005) e CPTI (1999), com enfoque em mapeamentos e estudos ambientais que abrangeram o espaço do entorno e da área de estudo, além de fornecerem embasamentos para o estudo referente aspectos geomorfológicos, em 
especial ás áreas úmidas. Em relação à interpretação das imagens Landsat, o presente trabalho baseou-se nas obras de Florenzano (2007) e Jensen (2009).

A identificação das áreas úmidas inseridas na unidade de mapeamento litoestratigráfico Ka $a_{\mathrm{V}}$, foi realizada por meio da interpretação de imagens de satélite Landsat 5 (Sensor TM), no período de 07/04/2010, disponibilizadas no banco de imagens do INPE (Instituto Nacional de Pesquisas Espaciais) nas faixas órbita/ponto: 222/75 e 222/76. O destaque de bandas específicas (543 e 457), dando enfoque principal à refletância dos recursos hídricos (assim como na vegetação relacionada), permitiu o levantamento das principais áreas úmidas presentes no local de estudo. Em seguida, foram efetuados trabalhos em campo, com a finalidade de reconhecer e comprovar as informações obtidas via interpretação das imagens.

\section{RESULTADOS E DISCUSSÃO}

Primeiramente, deve-se ressaltar que embora os fatores ambientais exerçam um importante papel sobre o meio físico, a presença antropogênica também é responsável por modificá-lo, causando efeitos que ocorrem em escalas temporais menores. Dentre estas modificações, a perda de fragmentos florestais no município de Anhumas, substituída há muito por monoculturas e pastoreio, impactou os recursos hídricos, alterando a paisagem natural. Atualmente, o uso do solo no município é marcado por pastagens, monoculturas de cana-deaçúcar e pequenas culturas. Em função dos fatores esculturais do relevo desta unidade (e da consequente dificuldade de mecanização), as culturas são diversificadas e ocupam polígonos menos extensos, embora que predomine, ainda, o capim exótico de pastagem e a cana-de-açúcar.

No primeiro cenário (Figura 3) a combinação RGB relacionada às bandas 543 torna possível identificar diferentes exemplos de coberturas, tais como malha urbana, rodovias e estradas. Em relação aos aspectos rurais observam-se claramente a mescla entre áreas ocupadas por pastagens, culturas como cana-de-açúcar e solos expostos. A coloração verde, aplicada para a vegetação, ressalta as espécies próximas aos cursos d'água, que possuem cor e textura diferentes daquelas associadas à agricultura, consistindo-se como matas ciliares. Observa-se, ainda, que esta combinação permite relacionar as formas dos ambientes fluviais (rios consequentes, subsequentes, cotovelos, dentre outros), em que se encontram relacionados às características estruturais do próprio modelado e da litologia regional.

No segundo cenário (Figura 4), a combinação RGB foi atribuída às bandas 457, permitindo um maior destaque para as áreas úmidas. Para este caso, em específico, a composição utilizada evidencia a incidência de corpos d'água superficiais, ressaltando a refletância hídrica nas imagens 
analisadas. Nota-se, nesta situação, que a ocorrência de planícies aluviais, fundos de vale e lençóis suspensos apresentam-se mais perceptível em relação ao cenário anterior. Os tons em azul-claro referem-se à áreas com maiores concentrações de sedimentos arenosos, como as estradas ou os depósitos cenozóicos situados sobre os córregos (característicos de assoreamentos). Por outro lado, atenta-se para o notável limite imposto por estas áreas úmidas em relação às áreas agricultáveis, pois o avanço destas práticas, sentido à proximidade dos córregos, somente não ocorre por conta de restrições naturais no próprio plantio e desenvolvimento destas espécies.

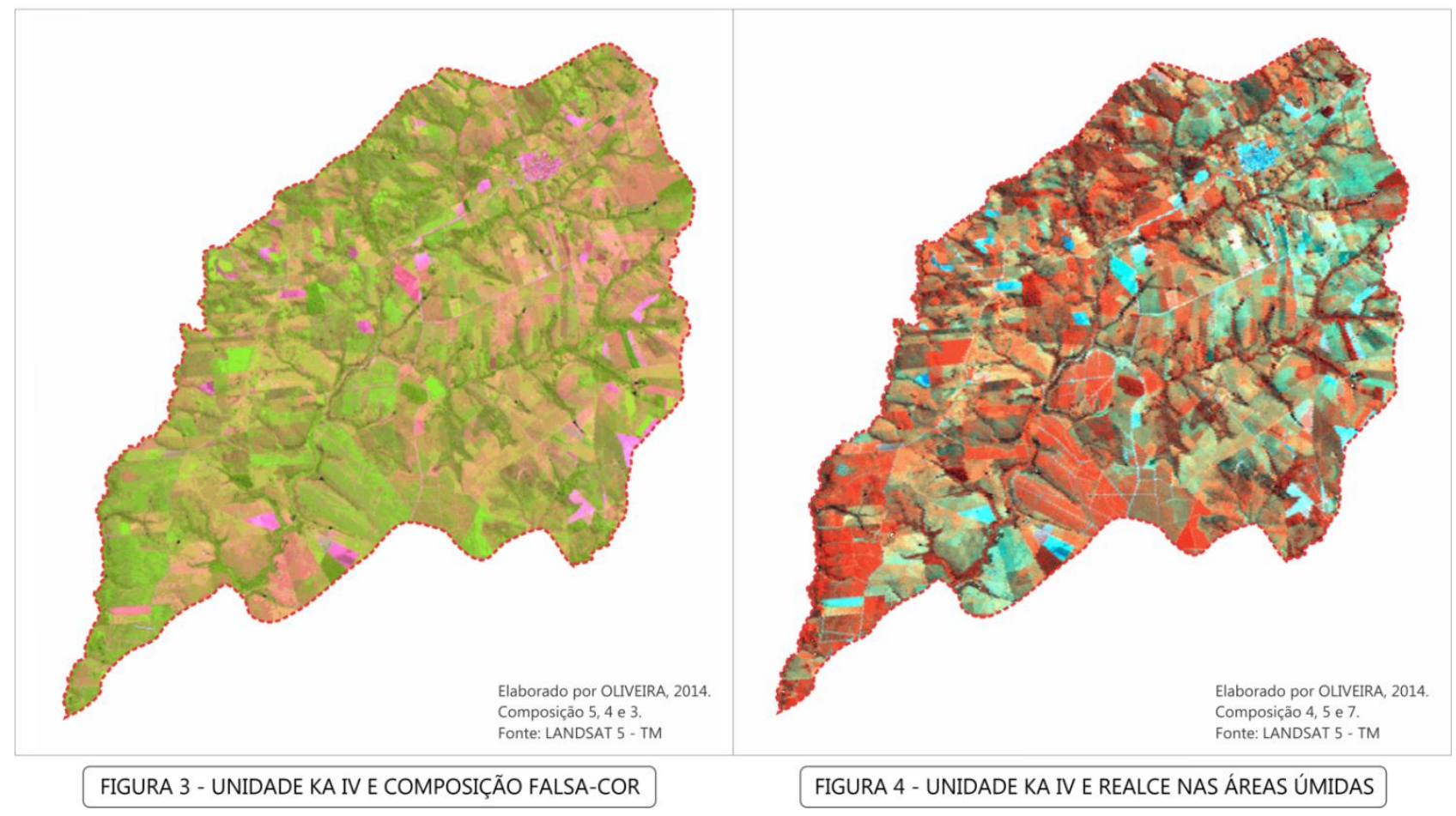

Figuras 3 e 4. Unidade Ka Iv e composição falsa-cor / e realce nas áreas úmidas.

Assim, a partir do levantamento efetuado faz-se possível observar claramente os processos atuais, sejam estes sob a influência natural ou antrópica no próprio meio físico. A predominância do solo podzólico vermelho-amarelo eutrófico (PVe8), comumente encontrado nesta porção do município, possibilita a maior retenção da água precipitada (quando comparado ao latossolo vermelho-amarelo, também comum no local), acumulando-a com maior facilidade. Essa impermeabilidade do solo, associada à declividade acentuada da área delimitada, determina um caráter dendrítico para a os canais fluviais desta unidade.

Este padrão de drenagem, por sua vez, encontra-se muitas vezes associado à ausência do controle estrutural do relevo, normalmente sobre rochas homogêneas, com poucas variações de substratos. Neste sentido, deve-se salientar que a diferença nos níveis de declividade expõe os 
lençóis suspensos em meia encosta, pois estes, devido à diferenciação composicional das camadas litológicas (ora com maiores frações de argilitos, ora com maiores frações de arenitos), resultam nos afloramentos da água infiltrada e acumulada (Figura 5).

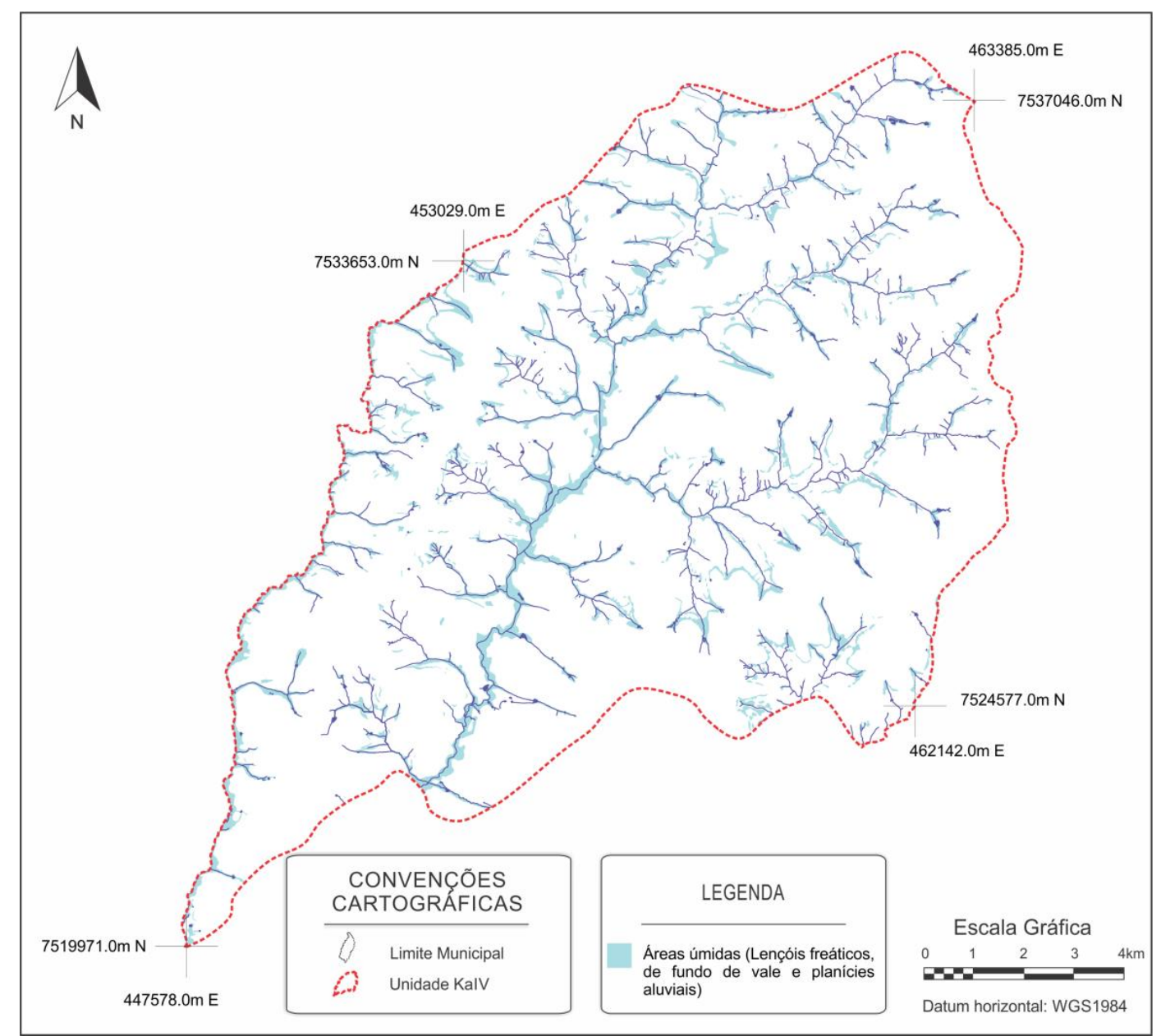

Figura 5. Carta das áreas úmidas na unidade de mapeamento Ka $\mathrm{IV}_{\mathrm{IV}}$. Fonte: Oliveira, 2014.

Em relação aos lençóis aflorantes em fundo de vale, estes se encontram próximos às planícies aluviais, sendo, muitas vezes, de difícil diferenciação quando observados em imagens Landsat com a resolução espacial de trinta metros. Assim como os lençóis suspensos, os de fundo de vale também estão sustentados por camadas semipermeáveis. A diferença, entretanto, encontra-se no sistema hidrogeológico regional, que exerce influência na maior disponibilidade hídrica do segundo. As planícies aluvias, portanto, estão presentes no ribeirão Anhumas, que cruza a unidade em sentido $\mathrm{N}-\mathrm{S}$. Em face da maior energia do relevo adjacente e da maior densidade de drenagem na $\mathrm{Ka}_{\mathrm{IV}}$, os sedimentos são transportados para as regiões seladoras, onde o relevo é mais plano, favorecendo a sedimentação destes ambientes e a eventual ocorrência dos leques aluviais. 
Em face à limitação na resolução espacial $(30 \times 30 m)$ da imagem do Landsat 5 e com a finalidade de comprovar as informações aqui relatadas, efetuou-se um trabalho de campo, onde se possibilitou averiguar as condições previamente descritas. Para tal, selecionaram-se pontos específicos dos quais fossem possíveis evidenciar o resultado obtido via a interpretação das áreas úmidas. A Figura 6, apresentada adiante, procura ilustrar as diferentes ocorrências de corpos d'água, enfatizando as características divergentes entre as condições a que se encontram estes afloramentos superficiais. Os trabalhos de campo confirmaram as diferenças entre os processos relacionados à distribuição dos recursos hídricos destacados nas imagens Landsat. Estas áreas úmidas, comumente associadas a brejos ou corpos d'água suspensos, são facilmente reconhecidas em razão da discrepância de vegetações tipicamente adaptadas ao solo em condições saturadas.

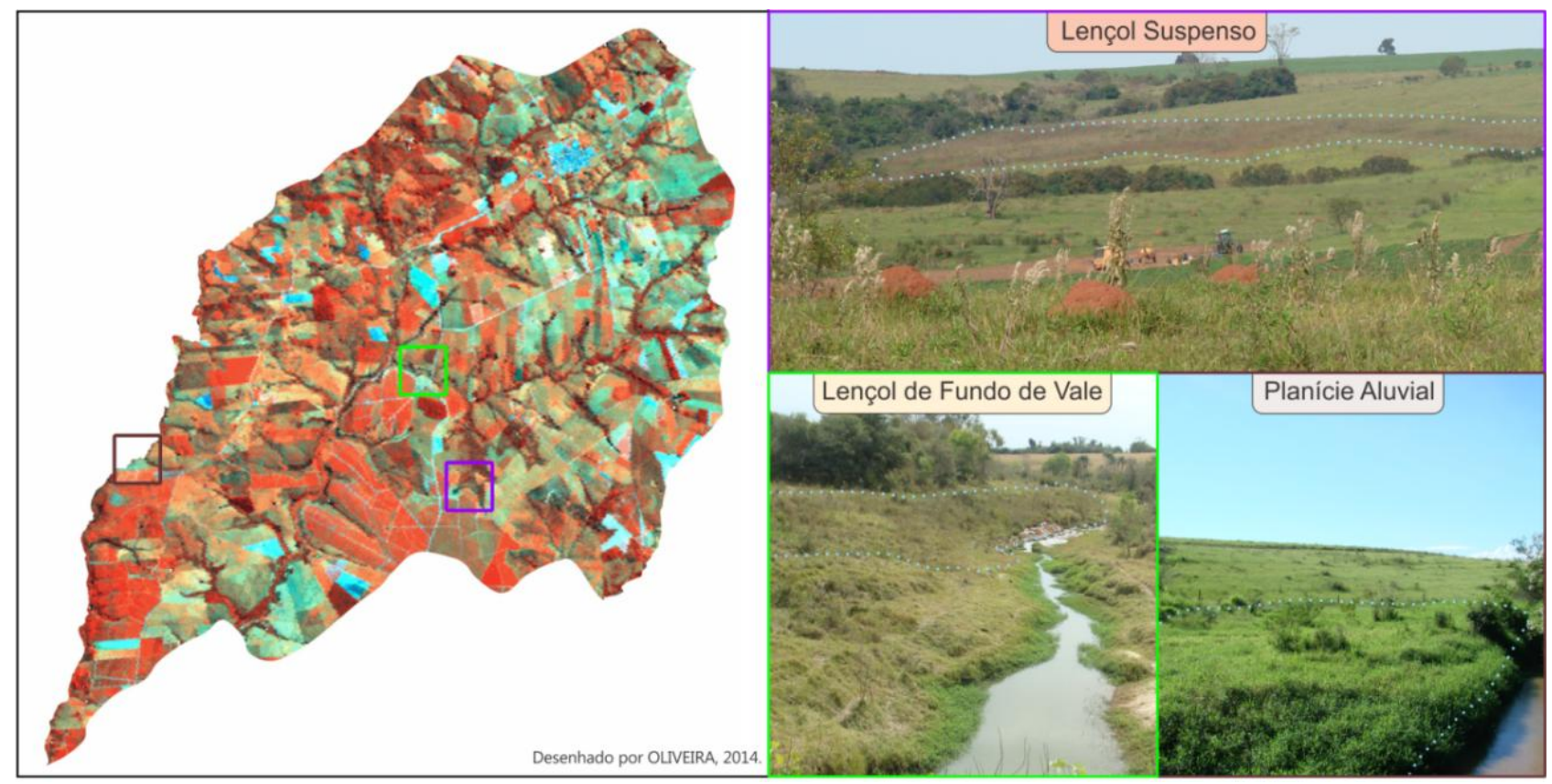

Figura 6. Tipos de áreas úmidas apontadas em campo.

\section{CONCLUSÃO}

Conforme ressaltado no decorrer do texto, os componentes naturais atuantes sobre determinada região possibilitam relacionar o comportamento dos recursos hídricos presentes, pois a própria distribuição hidrológica torna-se um reflexo destes elementos. No entanto, em razão da influência antrópica, estes ambientes apresentam diversas alterações das quais são consideráveis para a interpretação e avaliação do meio. Já relativo às técnicas empregadas na análise do meio físico, as imagens Landsat demonstram-se, para casos específicos, limitadas devido à resolução espacial de 30×30m. 
A distinção entre planícies aluviais e os lençóis de fundo de vale, por exemplo, tem sua classificação comprometida quando interpretados na imagem, pois estes ambientes encontram-se próximos, tornando-se necessário efetuar um aprofundamento nas condições geomorfológicas locais. Outro problema a ser ressaltado é a ocorrência de áreas úmidas inferiores ao tamanho do pixel da imagem utilizada $(30 \mathrm{~m})$, fator este muito comum no local, o que inviabiliza um estudo de escala de maior detalhe. Por conseguinte, entende-se que para estas situações, o uso de imagens com maior resolução facilita, em muito, a identificação destas áreas, embora que ainda não seja justificável ao pesquisador negligenciar o trabalho de campo.

\section{REFERÊNCIAS}

ALMEIDA, M. A. STEIN, D. P. MELO, M. S. BISTRICHI, C. A. PONÇANO, W. L. HASUI, Y. ALMEIDA. F. F. M. Geologia do Oeste Paulista e Áreas Fronteiriças dos Estados de Mato Grosso do Sul e Paraná. ANAIS do XXXI Gongresso Brasileiro de Geologia, Balneário de Camboriú, Santa Catarina, Vol. 3. 1980.

CPTI - Cooperativa de Serviços e Pesquisas Tecnológicas e Industriais. Relatório Zero da bacia hidrográfica do Pontal do Paranapanema. São Paulo: CPTI, 1999.

DAEE, Departamento de Águas e Energia Elétrica. Mapa de Águas Subterrâneas do Estado de São Paulo: escala 1:1.000.000: nota explicativa. 2005.

EMBRAPA. Mapa Pedológico do Estado de São Paulo: Legenda expandida. / Oliveira, J. B. et al. Campinas, Instituto agronômico; Rio de Janeiro: Embrapa solos, 1999.

FERNANDES, L. A. \& COIMBRA, A. M. Revisão estratigráfica da parte Oriental da Bacia Bauru (NeoCretáceo). Revista Brasileira de Geociências, V. 30, N. 4, São Paulo, p. 717-728, 2000.

FLORENZANO, T.G. Iniciação em sensoriamento remoto. São Paulo: Oficina de Textos, 2007.

IPT - Instituto de Pesquisas Tecnológicas do Estado de São Paulo. Mapa Geomorfológico do Estado de São Paulo, 1:1.000.000. São Paulo, IPT. v. 2. 1981.

JENSEN, J.R. Sensoriamento remoto do ambiente: uma perspectiva em recursos terrestres. São José dos Campos: Parêntese, 2009.

MELO, M. S.; STEIN, D. P.; ALMEIDA, M. A. Aspectos litoestratigráficos do Grupo Bauru. Encontro de Geologia e Hidrogeologia. São Paulo: SBG/ABAS, v. 9, 1982.

ROSS, J. S. Registro cartográfico dos fatos geomorfológicos e a questão da taxonomia do relevo. Rev. Geografia. São Paulo, IG-USP, 1992.

SOARES, P. C.; FIORI, A. P. Lógica e sistemática na análise e interpretação de fotografias aéreas em geologia. Campinas-São Paulo, p. 71-140, 1976. 